\title{
Fetal Tobacco Smoke Exposure in the Third Trimester of Pregnancy Is Associated with Atopic Eczema/Dermatitis Syndrome in Infancy
}

\author{
Miwa Shinohara, MD, $\mathrm{PhD}{ }^{1,2}$ and Kenji Matsumoto, $\mathrm{MD}, \mathrm{PhD}^{3}$
}

The manifestation of atopic dermatitis (AD) is initially nonatopic eczema in early infancy; the manifestations subsequently change in age-specific stages. Since allergen-specific T-helper 2 cells appear in the fetus primarily after the third trimester of pregnancy and rapidly mature during the first 6 months of life, different timings of tobacco smoke exposure may have different effects on AD. In this study, we investigated whether the timing of fetal or/and infantile tobacco smoke exposure affects the cumulative incidence of atopic eczema/dermatitis syndrome (AEDS) in infants in Japan. This cross-sectional study enrolled 1,177 parent-infant pairs, in which the infants were $>6$ months old. Parental allergic history, number of older siblings, physician-diagnosed AEDS and food allergy (FA), and the perinatal fetal and/or infantile tobacco smoke exposure timing after 28 weeks gestation and during the first 6 months of life were assessed using self-completed questionnaires. Fetal tobacco smoke exposure after 28 weeks gestation was significantly associated with higher cumulative incidence of AEDS in exposed infants than in unexposed infants: AEDS in all infants, $41.4 \%$ versus $34.0 \%$ (Chi-squared, $P=0.020$; adjusted odds ratio, 5.21; 95\% confidence interval, 1.08-25.15); AEDS in those without parental allergic history, $38.0 \%$ versus $26.6 \%$ (Chi-squared, $P=0.024$ ). Postnatal infantile tobacco smoke exposure timing was not significantly associated with cumulative incidence of AEDS. No significant associations were observed between any tobacco smoke exposure timings and the cumulative incidence of FA. Fetal tobacco smoke exposure during the third trimester of pregnancy was positively associated with AEDS in infancy and might induce epigenetic changes in the fetal allergen-specific immune responses.

Keywords: atopic dermatitis, cross-sectional study, eczema, environmental tobacco smoke, fetus, infant

\section{Introduction}

A TOPIC DERMATITIS (AD) is a chronic recurrent inflammatory skin disease caused by a complex network of epidermal barrier dysfunction and dysregulation of innate and adaptive immunity. ${ }^{1,2}$ The manifestations of AD vary according to age-specific stages; initially nonatopic dermatitis, such as infantile eczema, is initially exhibited, followed by $\mathrm{AD}$ after allergens sensitization, and, finally, autoallergic AD, as early as 1 year of age. ${ }^{1,3}$ According the World Allergy Organization, the term eczema has been proposed to replace the provisional term "atopic eczema/dermatitis syndrome (AEDS)," which includes both nonatopic eczema and atopic eczema. ${ }^{4}$ During recent decades, the prevalence of $\mathrm{AD}$ in children has been increasing in both developing and devel- oped countries. ${ }^{5-7}$ Because genetic changes in the general population take longer to occur, ${ }^{8}$ environmental factors that trigger genetic predisposition, epigenetic regulation, and/or the interactions between these factors might play an important, and complex, role in the increasing AD prevalence. ${ }^{9-11}$

Tobacco smoke exposure is a modifiable environmental risk factor for $\mathrm{AD}^{12,13}$ and bronchial asthma (BA). ${ }^{14}$ Tobacco smoke exposure during pregnancy has transgenerational and organ-specific effects, especially for the lungs. ${ }^{15}$ Regarding the skin, a recent systematic review and meta-analysis showed that active and passive exposure to smoke, but not maternal smoking during pregnancy, were associated with increased AD prevalence in both America and Africa. ${ }^{12}$ In contrast, in Asia, active smoking and maternal smoking during pregnancy, but not passive smoke exposure, were associated with increased $\mathrm{AD}$

${ }^{1}$ Department of Pediatrics, Ehime University Hospital, Toon, Japan.

${ }^{2}$ Department of Pediatrics, Kochi University, Nankoku, Japan.

${ }^{3}$ Department of Allergy and Clinical Immunology, National Research Institute for Child Health and Development, Tokyo, Japan.

(c) Miwa Shinohara and Kenji Matsumoto 2017; Published by Mary Ann Liebert, Inc. This is an Open Access article distributed under the terms of the Creative Commons Attribution License, which permits unrestricted use, distribution, and reproduction in any medium, provided the original work is properly cited. 
prevalence. Collectively, these results suggest that the effect of tobacco smoke exposure on the increasing incidence of $\mathrm{AD}$ may start during the fetal period in Japan.

The intrauterine environment, especially tobacco smoke and nutrition, can potentially induce permanent changes in metabolism and chronic disease susceptibility of the developing fetus, ${ }^{16}$ and influence the DNA methylation profile at birth. ${ }^{17}$ The fetal period is critical for programming the developing organs and immune function. ${ }^{18}$ During the fetal period in human, the $\operatorname{skin}^{19,20}$ and the lungs ${ }^{21}$ develop at around 5-6 weeks of gestation, whereas the airways are formed by the end of the first trimester of pregnancy, ${ }^{21}$ and "adult-like" skin features appear already during the second trimester of pregnancy. ${ }^{19,20}$ Furthermore, specific allergeninduced responses can occur from as early as 22 weeks gestation. $^{22}$ Initial T cell priming commonly occurs across the placenta, ${ }^{22}$ particularly against allergens encountered by the mother in the third trimester of pregnancy. ${ }^{23}$ After birth, neonatal allergen-specific T-helper 2 responses tend to decrease with age, especially within the first 6 months of life, in individuals who later develop atopic disease than in nonatopic individuals. The differences in immune function are a defining feature of the inductive phase of atopic disease. ${ }^{24}$

Because smoking-induced effects on organ growth and immune maturation in fetuses and infants occur in stages, the effect of tobacco smoke exposure on fetal or infantile diseases may differ on the basis of tobacco smoke exposure timing and/or atopic condition in the infants. In addition, prenatal tobacco smoke exposure reduces lung function (as measured by $\mathrm{FEV}_{1}$ ) at birth, and this is continuously observed throughout life. ${ }^{21,25}$ In contrast, maternal intake of fish oil in the third trimester of pregnancy has been shown to be associated with reduced asthma medication prescribed in children, except in lung function measures, compared with children whose mothers took olive oil. ${ }^{26}$ Taken together, these results and studies on the ontogeny of the fetus ${ }^{19,20}$ suggest that prenatal environmental factors might influence the development of the fetal organ structures during the first trimester of pregnancy, as well as the gradually maturing immune responses during and after the second trimester.

However, the critical "window of opportunity" of tobacco smoke exposure for AEDS remains unknown, despite its value for $\mathrm{AD}$ prevention and altering the course of the atopic march. We hypothesized that different tobacco smoke exposure timings may have different effects on the skin, in age-specific stages, as a result of the different mechanisms, and that the third trimester of pregnancy and first 6 months of life may be the critical "window of opportunity," because the immune response to environmental factors matures mostly during this period. ${ }^{22,23}$ In this study in Japan, we investigated whether the timing of fetal or infantile tobacco smoke exposure affects the cumulative incidence of physician-diagnosed AEDS in infants aged around 1 year.

\section{Materials and Methods}

\section{Study population}

This cross-sectional study conducted using written questionnaires completed by the guardians was performed during an annual large-scale medical checkup in April 2005 in Kochi, Japan. Parent-infant pairs with infants born in 2004 or 2005 were recruited. The large-scale medical checkup included in- fants in the general population of the Kochi prefecture. This has been performed annually in April since the end of World War II and is advertised in the Kochi Sinbun and Kochi Broadcasting newspaper. Approximately $40 \%$ of infants in the prefecture's general population enroll in this checkup each year. If the infants' guardians wish to participate, they mail a reservation request postcard to the newspaper that advertised the checkup; all respondents are eligible.

We have performed surveys of these large-scale medical checkups since 1999 and have reported the results in 2 previous studies. $^{27,28}$

\section{Questionnaire}

The self-completed written questionnaires, including our previously used questionnaires, ${ }^{27,28}$ were distributed before the checkup to all parent-infant pairs in March 2005 and were collected during checkup. To avoid recall bias as much as possible, the variables were transcribed by guardians using the maternal and child health handbook, which includes data on prenatal checkups, delivery, child development, and infant diseases, including infections and allergic diseases. This maternal and child health handbook is a public record note used by the Japanese government, and is distributed when a woman is confirmed to be pregnant by a doctor. ${ }^{29}$

The primary outcome was AEDS in the infant. The AEDS diagnosis was based on a "Yes" response to the question, "Has your infant ever been diagnosed with AEDS by a doctor?', The secondary outcome was the presence of food allergy (FA), which was determined similarly.

Based on the results of a literature review (Table 1) and our previous studies, ${ }^{27,28}$ the questionnaires also collected information on the following confounding factors: infant age, infant sex, parental allergic history, number of older brothers and older sisters, gestational weeks, infant height, body weight, head circumference at birth, and maternal and paternal ages at delivery.

Prenatal fetal tobacco smoke exposure was assessed separately using the question, "Do any of the following describe your tobacco smoke exposure? Choose the description that is most like your tobacco smoke exposure: (1) no one smoked, (2) someone smoked outside the home, (3) someone smoked at home, (4) mother smoked, or (5) father smoked.' Postnatal infantile tobacco smoke exposure was assessed in a similar manner. Tobacco smoke exposure was classified as no (response of "no one smoked") or yes (any other response). The timing of fetal or infantile tobacco smoke exposure was categorized into 4 groups: (1) before 28 weeks gestation, (2) from 28 weeks gestation until birth (third trimester), (3) for the first 6 months of life, and (4) after the first 6 months of life.

Parental allergic history was considered positive if the guardian answered "Yes" to the question, "Have you ever received a diagnosis of $\mathrm{AD}, \mathrm{FA}, \mathrm{BA}$, allergic rhinitis, or allergic conjunctivitis by a doctor?" Parental allergic history was classified as no (response of no to all conditions) or yes (response of yes to at least 1 condition).

\section{Statistical analysis}

Effects of fetal or infantile tobacco smoke exposure and parental allergic history on the cumulative incidence of AEDS and FA in the infants among the tobacco smoke exposure timing groups were estimated using Chi-square tests 
Table 1. General Characteristics of the Parent-Infant Pairs in Total and in Groups Separated According to Parental Atopic Dermatitis

\begin{tabular}{lccrr}
\hline & & \multicolumn{2}{c}{ Parental AD } & \multirow{2}{*}{$\mathrm{P}^{\mathrm{a}}$} \\
\cline { 3 - 4 } Variable & Total & No & Yes & $0.517^{\mathrm{b}}$ \\
\hline Infant sex (male/female) & $548 / 627$ & $344 / 405$ & $204 / 222$ & $<0.001^{\mathrm{b}}$ \\
Parental allergic history (no/yes) & $419 / 758$ & $419 / 331$ & $0 / 427$ & $0.936^{\mathrm{c}}$ \\
Infant age (months) & $12.0 \pm 3.0$ & $12.0 \pm 3.0$ & $12.0 \pm 3.1$ & $0.227^{\mathrm{c}}$ \\
Gestation weeks (weeks) & $32.4 \pm 1.6$ & $38.5 \pm 1.6$ & $38.6 \pm 1.8$ & $0.065^{\mathrm{c}}$ \\
Birth height (cm) & $48.4 \pm 3.5$ & $48.4 \pm 3.5$ & $48.5 \pm 3.5$ & $0.017^{\mathrm{c}}$ \\
Birth body weight (g) & $3005.8 \pm 442.9$ & $2981.5 \pm 442.9$ & $3049.4 \pm 457.5$ & $0.694^{\mathrm{c}}$ \\
Birth head circumstance (cm) & $33.1 \pm 2.3$ & $33.2 \pm 2.4$ & $33.1 \pm 2.1$ & $<0.001^{\mathrm{c}}$ \\
Maternal age at delivery (years) & $31.1 \pm 4.5$ & $31.5 \pm 4.5$ & $30.4 \pm 4.5$ & $0.870^{\mathrm{c}}$ \\
No. of older brothers & $0.4 \pm 0.7$ & $0.4 \pm 0.6$ & $0.4 \pm 0.6$ & $0.267^{\mathrm{c}}$ \\
No. of older sisters & $0.4 \pm 0.6$ & $0.4 \pm 0.7$ & $0.4 \pm 0.7$ & $0.823^{\mathrm{b}}$ \\
Fetal or/and infantile tobacco smoke & $173 / 1,032(14.4)$ & $109 / 641(14.5)$ & $64 / 391(14.1)$ & $0.561^{\mathrm{c}}$ \\
$\quad$ exposure (no/yes) & & & & \\
Maternal active tobacco smoke (no/yes) & $57 / 807(6.6)$ & $36 / 540(6.3)$ & $21 / 267(7.3)$ & 0.5 \\
\hline
\end{tabular}

Data represented as $n(\%)$ or mean \pm standard deviation, unless otherwise indicated.

${ }^{a} P<0.050$, analyzed an association between the groups separated according to parental AD (Chi-square test).

${ }^{\mathrm{b}}$ Chi-square test.

${ }^{\mathrm{c}}$ Mann-Whitney test.

$\mathrm{AD}$, atopic dermatitis.

and Fisher's exact tests. Adjusted odds ratios (aORs) and 95\% confidence intervals (CIs) were estimated using multiple logistic regression analyses adjusted for infant age, infant sex, parental allergic diseases, number of older brothers, number of older sisters, gestational weeks, and maternal age at infant's birth. The $95 \%$ CIs that did not cross 1 were considered statistically significant. To confirm the validity of the logistic regression model, we used the Hosmer-Lemeshow goodnessof-fit test and considered the model valid with $P>0.050$. The Hosmer-Lemeshow test indicated that all models had significantly high goodness-of-fit. All analyses were calculated using STATA software (release 10.1; StataCorp, College Station, TX).

\section{Ethics}

The study was approved by the Ethical Committees of Kochi University, Ehime University Hospital, and the respective local authorities and conformed to the tenets of the Declaration of Helsinki. Written informed consent was obtained from the guardians of all patients.

\section{Results}

\section{Subjects}

The self-completed questionnaires were distributed by the Kochi Sinbun and Kochi Broadcasting newspaper to all infant-parent pairs in March 2005 before the large-scale medical checkup. The questionnaires were collected from the participants in the same place where the checkup was conducted. The response rate was $97.2 \%(1,436 / 1,476)$. To investigate the effects of tobacco smoke on the fetal or infantile exposure timing from the prenatal period to the first 6 months of life, data for $82.0 \%(1,177 / 1,436)$ of the parentinfant pairs in which the infant was $>6$ months old (627 boys, 548 girls, mean age $12.0 \pm 3.0$ months, range 7-18 months) were extracted for further analysis (Table 1).

As a result, maternal active tobacco smoke was not significantly associated with parental $\mathrm{AD}$, that is, maternal $\mathrm{AD}$ and/or paternal $\mathrm{AD}(6.3 \%$ vs. $7.3 \%$; $P=0.561$; Table 1$)$.

\section{Associations between fetal or infantile tobacco smoke exposure timing and AEDS}

The cumulative incidence of AEDS was significantly higher in exposed infants than in unexposed infants only in the third trimester timing group $(41.4 \%$ vs. $34.0 \%$; $P=0.020$; Fig. 1).

\section{Associations between fetal or infantile tobacco smoke exposure timing and AEDS according to the parental allergic history}

In infants with a parental allergic history, the cumulative incidence of ADES was not significantly different between the exposed and unexposed infants in any of the tobacco smoke exposure timing groups (Fig. 2a). In contrast, among those without a parental allergic history, the cumulative incidence of AEDS was significantly higher in exposed infants than in unexposed infants ( $38.0 \%$ vs. $26.6 \% ; P=0.024$; Fig. 2b) only in the third trimester timing group.

\section{aORs for AEDS based on the fetal or infantile tobacco smoke exposure timing}

On the basis of the adjusted logistic regression analyses, only fetal tobacco smoke exposure during the third trimester was significantly associated with a higher cumulative incidence of AEDS (aOR, 5.21; 95\% CI, 1.08-25.15; Table 2) than in unexposed infants.

\section{Associations between fetal or infantile tobacco smoke exposure timing and $F A$}

The cumulative incidence of FA was not significantly different between exposed and unexposed infants for any tobacco smoke exposure timing group or when analyzed according to the parental allergic history in both the Chisquared tests (Table 3) and adjusted logistic regression analyses (Table 4). 

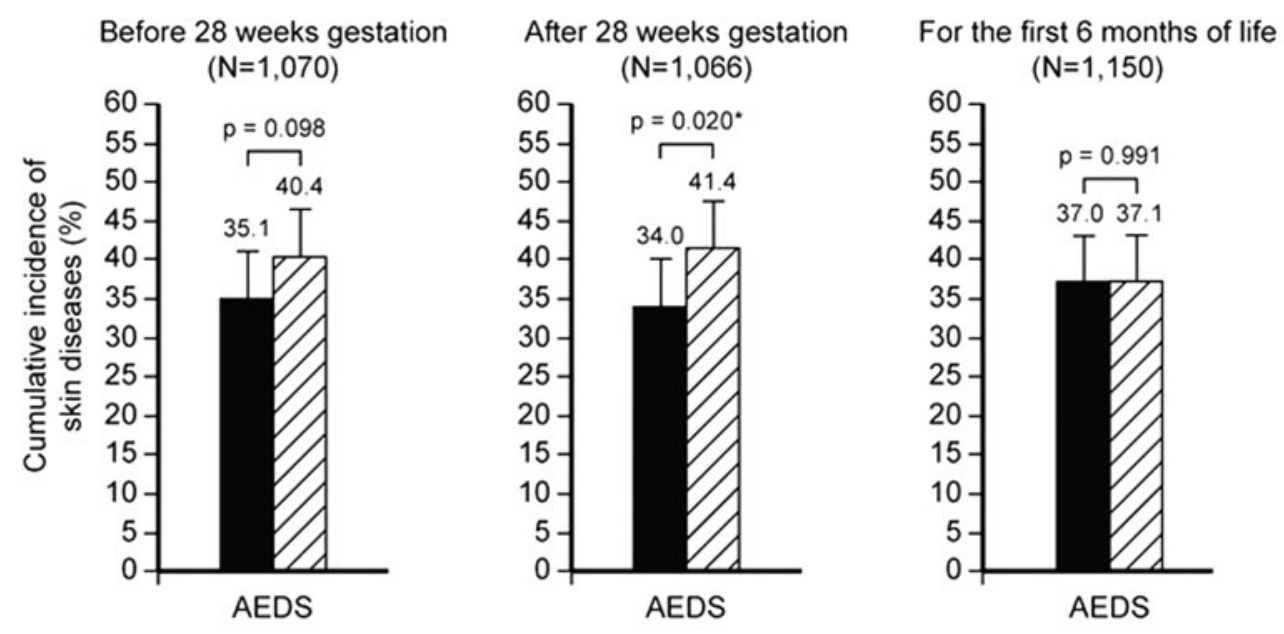

After the first 6 months of life

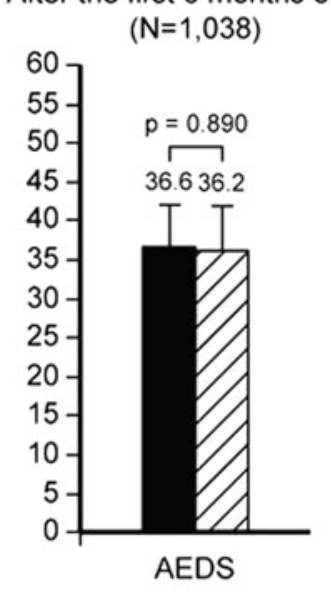

Tobacco smoke unexposed infants $\square$ Tobacco smoke exposed infants

FIG. 1. Cumulative incidence of AEDS in all infants. AEDS, atopic eczema/dermatitis syndrome. $* P<0.050$, analyzed an association between tobacco smoke unexposed infants and tobacco smoke exposed infants (Chi-square test).

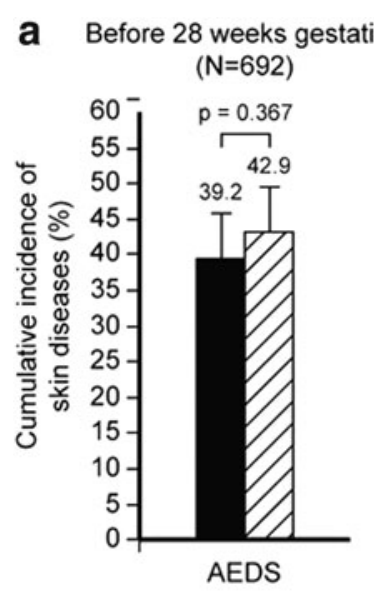

b Before 28 weeks gestation
$(\mathrm{N}=378)$

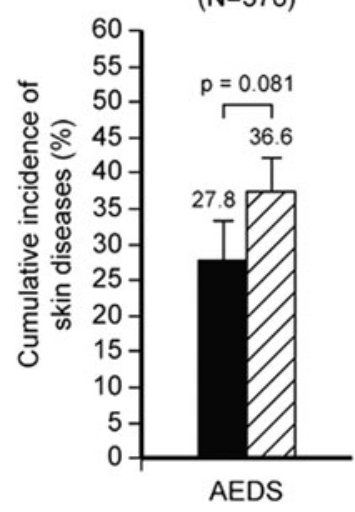

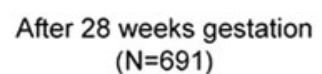

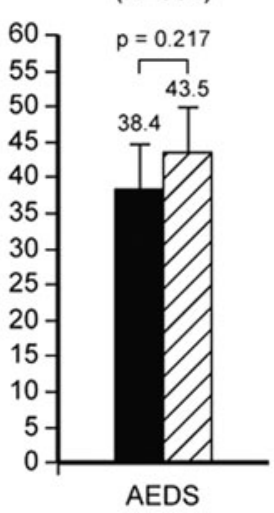

After 28 weeks gestation
$(\mathrm{N}=375)$

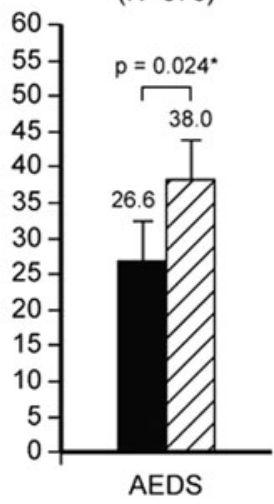

For the first 6 months of life After the first 6 months of life $(\mathrm{N}=741)$
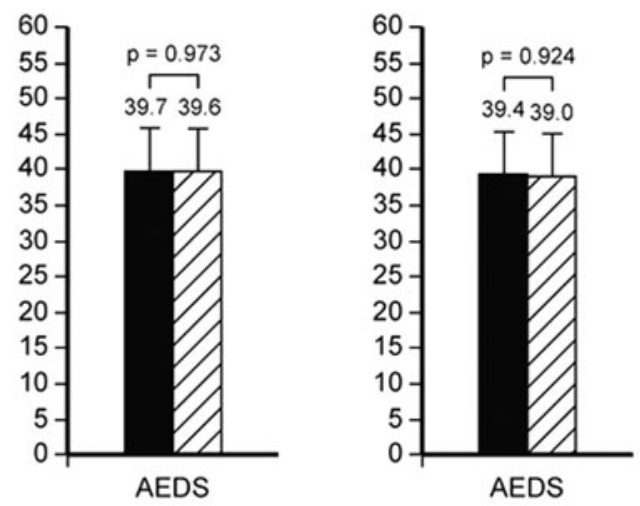

For the first 6 months of life After the first 6 months of life
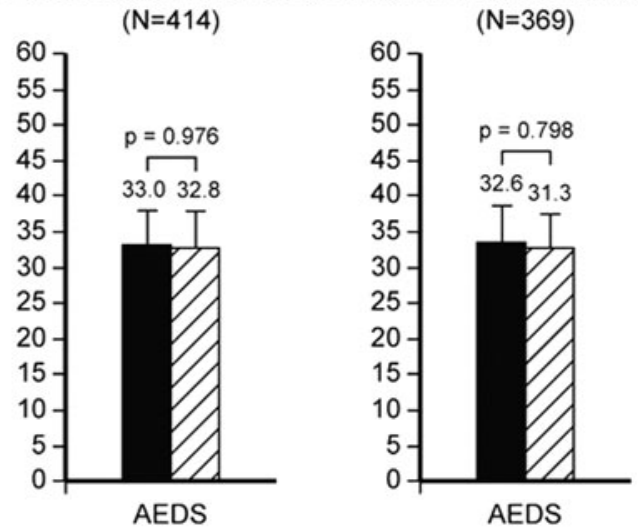

Tobacco smoke unexposed infants $\square$ Tobacco smoke exposed infants

FIG. 2. Cumulative incidence of AEDS in infants with (a) and without (b) the parental allergic history. The groups are compared using the Chi-square test $(n>5)$ or Fisher's exact test $(n \leq 5) * P<0.050$, analyzed an association between tobacco smoke unexposed infants and tobacco smoke exposed infants (Chi-square test). 
Table 2. Crude and Adjusted Associations Between the Tobacco Smoke Exposure Timing And the Cumulative Incidence of AEDS in All Infants $(N=1,177)$

\begin{tabular}{|c|c|c|c|c|c|}
\hline Variable & $A E D S, \mathrm{n}(\%)$ & Crude OR & $95 \% C I$ & Adjusted $^{\mathrm{a}}$ OR & $95 \% C I$ \\
\hline \multicolumn{6}{|c|}{ Parental allergic history } \\
\hline No & $131 / 398(32.9)$ & 1 & & 1 & \\
\hline Yes & $254 / 637$ (39.9) & 1.35 & $1.04-1.76^{\mathrm{b}}$ & 1.24 & $0.77-1.99$ \\
\hline Infant age & & 1.02 & $0.97-1.08$ & 1.01 & $0.94-1.09$ \\
\hline \multicolumn{6}{|l|}{ Infant sex } \\
\hline Male & $228 / 560(40.7)$ & 1 & & 1 & \\
\hline Female & $157 / 474(33.1)$ & 0.72 & $0.56-0.93$ & 0.70 & $0.44-1.10$ \\
\hline \multicolumn{6}{|c|}{ Tobacco smoke exposure timing } \\
\hline \multicolumn{6}{|c|}{ Before 28 weeks gestation } \\
\hline No & $141 / 402(35.1)$ & 1 & & 1 & \\
\hline Yes & $216 / 535(40.4)$ & 1.25 & $0.96-1.64$ & 0.27 & $0.06-1.31$ \\
\hline \multicolumn{6}{|c|}{ After 28 weeks gestation } \\
\hline No & $139 / 409(34.0)$ & 1 & & 1 & \\
\hline Yes & $217 / 524(41.4)$ & 1.37 & $1.05-1.80^{\mathrm{b}}$ & 5.21 & $1.08-25.15^{\mathrm{b}}$ \\
\hline \multicolumn{6}{|c|}{ For the first 6 months of life } \\
\hline No & $177 / 478(37.0)$ & 1 & & 1 & \\
\hline Yes & $202 / 545(37.1)$ & 1.00 & $0.78-1.29$ & 0.92 & $0.25-3.43$ \\
\hline \multicolumn{6}{|c|}{ After the first 6 months of life } \\
\hline No & $156 / 426(36.6)$ & 1 & & 1 & \\
\hline Yes & $178 / 492(36.2)$ & 0.98 & $0.75-1.28$ & 1.42 & $0.38-5.26$ \\
\hline
\end{tabular}

${ }^{a}$ Logistic regression analyses were adjusted for infant age; infant sex; parental allergic history; number of older brothers; number of older sisters; gestational weeks; maternal ages at delivery; tobacco smoke exposure before 28 weeks gestation, tobacco smoke exposure after 28 weeks gestation, tobacco smoke exposure for the first 6 months of life, and tobacco smoke exposure after the first 6 months of life.

b95\% CI exclusive of 1 .

AEDS, atopic eczema/dermatitis syndrome; CI, confidence interval; OR, odds ratio.

\section{Discussion}

In this cross-sectional study, tobacco smoke exposure during the third trimester was significantly associated with a higher cumulative incidence of AEDS in exposed infants than in unexposed infants in Japan. Furthermore, the association with AEDS remained in the adjusted logistic regression analysis. The cumulative incidence of AEDS was significantly higher in the exposed infants than in the un- exposed infants without parental allergic history, but not in those with parental allergic history. In contrast, postnatal tobacco smoke exposure did not significantly affect the cumulative incidence of AEDS. Neither the prenatal nor the postnatal tobacco smoke exposure timing affected the cumulative incidence of FA.

The critical window of tobacco smoke exposure timing for AEDS has been debated. ${ }^{12,17,30}$ Similar to our results in Japan, a previous questionnaire-based cross-sectional study

Table 3. Association Between the Tobacco Smoke Exposure Timing and the Cumulative Incidence of Food Allergy in All Infants and Those Separated According to the Parental Allergic History

\begin{tabular}{|c|c|c|c|c|c|c|}
\hline \multirow[b]{4}{*}{ Tobacco smoke exposure timing } & \multirow{2}{*}{\multicolumn{2}{|c|}{ Total $(\mathrm{n}=1,177)$}} & \multicolumn{4}{|c|}{ Parental allergic history } \\
\hline & & & \multicolumn{2}{|c|}{ Yes $(\mathrm{n}=758)$} & \multicolumn{2}{|c|}{ No $(\mathrm{n}=419)$} \\
\hline & $F A$ & \multirow[b]{2}{*}{$\mathrm{P}^{\mathrm{a}}$} & $F A$ & \multirow[b]{2}{*}{$\mathrm{P}^{\mathrm{a}}$} & $F A$ & \multirow[b]{2}{*}{$\mathrm{P}^{\mathrm{a}}$} \\
\hline & Yes/no (\%) & & Yes/no (\%) & & Yes/no (\%) & \\
\hline \multicolumn{7}{|l|}{ Before 28 weeks gestation } \\
\hline No & $15 / 391(3.8)$ & \multirow[t]{2}{*}{0.801} & $10 / 237(4.1)$ & \multirow[t]{2}{*}{0.702} & $5 / 139(3.5)$ & \multirow[t]{2}{*}{0.583} \\
\hline Yes & $22 / 528(4.2)$ & & $15 / 303(4.7)$ & & $7 / 203(3.3)$ & \\
\hline \multicolumn{7}{|l|}{ After 28 weeks gestation } \\
\hline No & $14 / 400(3.5)$ & \multirow{2}{*}{0.462} & $9 / 235(3.7)$ & \multirow{2}{*}{0.453} & $5 / 151(3.2)$ & \multirow{2}{*}{0.543} \\
\hline Yes & $23 / 515(4.5)$ & & $16 / 304(5.0)$ & & 7/188 (3.6) & \\
\hline \multicolumn{7}{|l|}{ For the first 6 months of life } \\
\hline No & 22/471 (4.7) & \multirow[t]{2}{*}{0.401} & $14 / 264(5.0)$ & \multirow{2}{*}{0.400} & $8 / 185(4.2)$ & \multirow{2}{*}{0.761} \\
\hline Yes & $19 / 526(3.6)$ & & $12 / 317(3.7)$ & & 7/190 (3.6) & \\
\hline \multicolumn{7}{|l|}{ After the first 6 months of life } \\
\hline No & $22 / 424(5.2)$ & \multirow[t]{2}{*}{0.291} & $14 / 233(5.7)$ & \multirow[t]{2}{*}{0.243} & $8 / 169(4.5)$ & \multirow[t]{2}{*}{0.809} \\
\hline Yes & $18 / 481(3.7)$ & & $11 / 295(3.6)$ & & $7 / 168(4.0)$ & \\
\hline
\end{tabular}

${ }^{\mathrm{a}}$ Chi-square test.

FA, food allergy. 
Table 4. Crude and Adjusted Associations Between the Tobacco Smoke Exposure Timing and the Cumulative InCidence of Food Allergy in All Infants $(N=1,177)$

\begin{tabular}{|c|c|c|c|c|c|}
\hline \multirow[b]{2}{*}{ Variable } & $F A$ & \multirow[b]{2}{*}{ Crude OR } & \multirow[b]{2}{*}{$95 \% C I$} & \multirow[b]{2}{*}{ Adjusted $^{\mathrm{a}} O R$} & \multirow[b]{2}{*}{$95 \% C I$} \\
\hline & $\mathrm{n}(\%)$ & & & & \\
\hline \multicolumn{6}{|c|}{ Parental allergic history } \\
\hline No & $15 / 393(3.8)$ & 1 & & 1 & \\
\hline Yes & $26 / 615(4.2)$ & 1.11 & $0.58-2.13$ & 0.90 & $0.31-2.61$ \\
\hline Infant age & & 1.30 & $1.14-1.48$ & 1.28 & $1.07-1.53^{\mathrm{b}}$ \\
\hline \multicolumn{6}{|l|}{ Infant sex } \\
\hline Male & $12 / 465(2.6)$ & 1 & & 1 & \\
\hline Female & $29 / 542(5.4)$ & 0.47 & $0.24-0.93$ & 0.49 & $0.16-1.53$ \\
\hline \multicolumn{6}{|c|}{ Tobacco smoke exposure timing } \\
\hline \multicolumn{6}{|c|}{ Before 28 weeks gestation } \\
\hline No & $15 / 391(3.8)$ & 1 & & 1 & \\
\hline Yes & $22 / 528(3.8)$ & 1.09 & $0.56-2.13$ & 0.26 & $0.01-6.70$ \\
\hline \multicolumn{6}{|c|}{ After 28 weeks gestation } \\
\hline No & $14 / 400(3.5)$ & 1 & & 1 & \\
\hline Yes & $23 / 515(4.5)$ & 1.29 & $0.65-2.54$ & 2.37 & $0.09-59.53$ \\
\hline \multicolumn{6}{|c|}{ For the first 6 months of life } \\
\hline No & $19 / 526(3.6)$ & 1 & & 1 & \\
\hline Yes & $22 / 471(4.7)$ & 0.76 & $0.41-1.43$ & 0.77 & $0.03-19.38$ \\
\hline \multicolumn{6}{|c|}{ After the first 6 months of life } \\
\hline No & $22 / 424(5.2)$ & 1 & & 1 & \\
\hline Yes & $18 / 481(3.7)$ & 0.71 & $0.38-1.34$ & 0.47 & $0.02-11.82$ \\
\hline
\end{tabular}

${ }^{a}$ Logistic regression analyses were adjusted for infant age; infant sex; parental allergic history; number of older brothers; number of older sisters; gestational weeks; maternal ages at delivery; tobacco smoke exposure before 28 weeks gestation, tobacco smoke exposure after 28 weeks gestation, tobacco smoke exposure for the first 6 months of life, and tobacco smoke exposure after the first 6 months of life.

${ }^{\mathrm{b}} 95 \%$ CI exclusive of 1.

CI, confidence interval; FA, food allergy; OR, odds ratio.

in Greece showed that passive maternal exposure to tobacco smoke, mainly during the third trimester, was significantly associated with a pruritic rash in 12- to 72-month-old children. ${ }^{30}$ Furthermore, a previous systematic review and metaanalysis reported that the effect of tobacco smoke exposure timing on $\mathrm{AD}$ differs by residential region and/or race. Whereas, in Asia, postnatal active smoking and maternal smoking during pregnancy, but not postnatal passive smoke exposure, were associated with an increased AD prevalence from childhood to adulthood. ${ }^{12}$ Despite differences in the age and regions, these previous results concur with those of this study.

Interestingly, tobacco smoke exposure during the fetal period has transgenerational and organ-specific effects. Based on an association between grandmaternal smoking during pregnancy and an increased risk of BA in her grandchildren, it has been speculated that the inheritance of asthma susceptibility is mediated through epigenetic mechanisms, such as altered DNA methylation patterns in fetal oocytes. ${ }^{15}$ Although exposure at $>36$ weeks gestation was not investigated, a recent human study found that maternal smoking after 24 weeks gestation, but not before 12 weeks gestation, altered DNA methylation in newborns, ${ }^{17}$ highlighting the tissue-specific nature of epigenetic responses in cord blood mononuclear cells, placenta, and buccal mucosa to in utero tobacco smoke exposure and the postnatal stability of smoking-induced epigenetic changes 18 months postbirth. In addition, previous articles on, ${ }^{21,25,26}$ including the ontogeny of the human fetus, ${ }^{19,20}$ suggest that fetal tobacco smoke exposure might influence the development of fetal structures during the first trimester of pregnancy, after which it gradually affects the programming of immune responses during the third trimester of pregnancy. Supporting this speculation, when we categorized the infants by parental history of allergic diseases, the so-called atopic risk, the effect of tobacco smoke exposure during the third trimester of pregnancy remained only in the infants without atopic risk.

In contrast, in a prospective birth cohort study, the risk of eczema with sensitization, but not eczema without sensitization, in 4-year-old children increased as a result of maternal prenatal smoking during any trimester, parental smoking during the child's first month, or both. ${ }^{31}$ In a cross-sectional study, current tobacco smoke exposure by atopic parents was significantly associated with AD risk in 6.5-year-old children. ${ }^{32}$ However, the $\mathrm{AD}$ diagnosis was defined using a standardized dermatological examination, not by examination for atopic sensitization in the children. The discrepancies among ours and previous studies may be explained by differences in the subject age and atopic condition, because AD generally manifests as nonatopic eczema in infancy, followed by AD after allergens sensitization, and, finally as autoallergic AD in one-third of patients with $\mathrm{AD},{ }^{2}$ as early as 1 year of age. ${ }^{1,3}$ In addition, $\sim 60 \%$ of all AD cases occur during the first year ${ }^{1}$; thus, we used the AEDS criteria, which include both nonatopic eczema and atopic eczema ${ }^{4}$ in this study of infants aged $\sim 1$ year. Therefore, the mechanism for the effects of tobacco smoke exposure during the third trimester of pregnancy on AEDS may be mediated by epigenetic regulations during the fetal and early infantile periods and then by atopy-related genetic factors during childhood, in age-specific stages.

The positive association between tobacco smoke exposure during the third trimester of pregnancy and AEDS was an important finding of our study and remained in the adjusted regression analysis. It should be noted that the sample size in 
the adjusted logistic regression analysis was relatively small in this study. However, we used the Hosmer-Lemeshow goodness-of-fit test to analyze the results of the adjusted logistic regression analyses. ${ }^{33}$

The results of 2 previous studies in $\operatorname{Japan}^{34,35}$ are partially consistent with those of this study regarding the effect of postnatal tobacco smoke exposure timing. In 1 study, a questionnaire-based prospective cohort study, maternal smoking during pregnancy and environmental tobacco smoke exposure at 2-9 months postdelivery did not influence the development of AD in 16-24-month-old infants. ${ }^{34}$ In the other study, a questionnaire-based cross-sectional study, there was no measurable associations between maternal smoking during pregnancy, smoking by adult household members after birth, or both, and the prevalence of eczema in 3 -year-old children. ${ }^{35}$ The discrepancy in the effects of tobacco smoke exposure on $\mathrm{AD}$ may be related to differences in the age-specific stages of eczema, type of skin diseases, allergic sensitization, residual regions, AD criteria, ${ }^{12,31}$ the route, timing, duration, and/or amount of tobacco smoke exposure, ${ }^{36,37}$ and participant's age. ${ }^{37}$

To further determine the effect of the tobacco smoke exposure timing on AEDS, we also investigated the associations between the tobacco smoke exposure timing and the cumulative incidence of FA, which were not significant. Therefore, the effects of the tobacco smoke exposure timing may be specific to AEDS in infancy.

There are some limitations in this study. First, AEDS was defined as a diagnosis by a physician and was identified using the questionnaires. Thus, allergic sensitizations were not investigated. However, this is in concordance with previous studies performed using questionnaires. ${ }^{30,32,34-36,38}$ Second, the cross-sectional study design meant that we could not identify any causation. Third, information about the frequency, duration, and/or amount of tobacco smoke exposure was only obtained using the questionnaires, and urinary cotinine was not measured. However, the adverse health effects of tobacco smoke exposure are considered to be associated with long exposure periods, and urinary cotinine reflects exposure over the past 1-2 days; therefore, tobacco exposure assessments are reportedly useful. ${ }^{39}$ Finally, in addition to tobacco smoke exposure, nutrition is an important environmental factor that influences the development of AD. In this study, we also assessed nutrition, similar to our previous studies $^{27,28}$; however, the sample size was relatively small to perform the adjusted logistic regression analysis. ${ }^{33}$

In conclusion, to our knowledge, this is the first crosssectional study to investigate the associations between prenatal and postnatal tobacco smoke exposure timing and the cumulative incidence of early onset eczema types in infancy. Tobacco smoke exposure during the third trimester of pregnancy was found to be associated with a higher cumulative incidence of AEDS, especially in all infants and those without parental allergic diseases. Therefore, a critical "window of opportunity" of tobacco smoke exposure for eczema in early infancy may be the third trimester of pregnancy, and the exposure timing may have different effects on eczema because of the agespecific stages of subclinical or allergic inflammation mediated by smoking-induced epigenetic mechanisms of fetal immune responses. A further prospective cohort study investigating whether smoking-induced epigenetic changes in fetal and neonatal $\mathrm{T}$ cells cause susceptibility to AEDS in early infancy may provide evidence for new preventive strategies for AD.

\section{Acknowledgments}

We would like to thank all of the children and guardians who participated in this research. We would like to thank Kochi Shinbun and Kochi Broadcasting for their assistance in recruiting participants and recovery of questionnaires.

Source of Financial Support: The authors received no funding in the form of grants or other on behalf of this research.

\section{Author Disclosure Statement}

No competing financial interests exist.

\section{References}

1. Bieber T. Atopic dermatitis. N Engl J Med 2008;358:14831494.

2. D'Auria E, Banderali G, Barberi S, Gualandri L, Pietra B, Riva E, Cerri A. Atopic dermatitis: recent insight on pathogenesis and novel therapeutic target. Asian Pac J Allergy Immunol 2016;34:98-108.

3. Mothes N, Niggemann B, Jenneck C, Hagemann T, Weidinger S, Bieber T, Valenta R, Novak N. The cradle of IgE autoreactivity in atopic eczema lies in early infancy. J Allergy Clin Immunol 2005;116:706-709.

4. Johansson SG, Bieber T, Dahl R, Friedmann PS, Lanier BQ, Lockey RF, Motala C, Ortega Martell JA, Platts-Mills TA, Ring J, Thien F, Van Cauwenberge P, Williams HC. Revised nomenclature for allergy for global use: report of the Nomenclature Review Committee of the World Allergy Organization, October 2003. J Allergy Clin Immunol 2004; 113:832-836.

5. Williams H, Stewart A, von Mutius E, Cookson W, Anderson HR. Is eczema really on the increase worldwide? J Allergy Clin Immunol 2008;121:947-954.e15.

6. Odhiambo JA, Williams HC, Clayton TO, Robertson CF, Asher MI. Global variations in prevalence of eczema symptoms in children from ISAAC Phase Three. J Allergy Clin Immunol 2009;124:1251-1258 e23.

7. Weidinger S, Novak N. Atopic dermatitis. Lancet 2016; 387:1109-1122.

8. Wills-Karp M, Santeliz J, Karp CL. The germless theory of allergic disease: revisiting the hygiene hypothesis. Nat Rev Immunol 2001;1:69-75.

9. Ahn K. The role of air pollutants in atopic dermatitis. J Allergy Clin Immunol 2014;134:993-999; discussion 1000.

10. Leung DY, Guttman-Yassky E. Deciphering the complexities of atopic dermatitis: shifting paradigms in treatment approaches. J Allergy Clin Immunol 2014;134:769-779.

11. Liang Y, Chang C, Lu Q. The genetics and epigenetics of atopic dermatitis-filaggrin and other polymorphisms. Clin Rev Allergy Immunol 2016;51:315-328.

12. Kantor R, Kim A, Thyssen JP, Silverberg JI. Association of atopic dermatitis with smoking: a systematic review and meta-analysis. J Am Acad Dermatol 2016;75:11191125.e1.

13. Saulyte J, Regueira C, Montes-Martinez A, Khudyakov P, Takkouche B. Active or passive exposure to tobacco smoking and allergic rhinitis, allergic dermatitis, and food allergy in adults and children: a systematic review and meta-analysis. PLoS Med 2014;11:e1001611. 
14. Silvestri M, Franchi S, Pistorio A, Petecchia L, Rusconi F. Smoke exposure, wheezing, and asthma development: a systematic review and meta-analysis in unselected birth cohorts. Pediatr Pulmonol 2015;50:353-362.

15. Li YF, Langholz B, Salam MT, Gilliland FD. Maternal and grandmaternal smoking patterns are associated with early childhood asthma. Chest 2005;127:1232-1241.

16. Waterland RA, Michels KB. Epigenetic epidemiology of the developmental origins hypothesis. Annu Rev Nutr 2007;27:363-388.

17. Novakovic B, Ryan J, Pereira N, Boughton B, Craig JM, Saffery R. Postnatal stability, tissue, and time specific effects of AHRR methylation change in response to maternal smoking in pregnancy. Epigenetics 2014;9:377-386.

18. Renz H, Brandtzaeg P, Hornef M. The impact of perinatal immune development on mucosal homeostasis and chronic inflammation. Nat Rev Immunol 2012;12:9-23.

19. Visscher M, Narendran V. The ontogeny of skin. Adv Wound Care (New Rochelle) 2014;3:291-303.

20. Elbe-Burger A, Schuster C. Development of the prenatal cutaneous antigen-presenting cell network. Immunol Cell Biol 2010;88:393-399.

21. Postma DS, Bush A, van den Berge M. Risk factors and early origins of chronic obstructive pulmonary disease. Lancet 2015;385:899-909.

22. Jones AC, Miles EA, Warner JO, Colwell BM, Bryant TN, Warner JA. Fetal peripheral blood mononuclear cell proliferative responses to mitogenic and allergenic stimuli during gestation. Pediatr Allergy Immunol 1996;7:109-116.

23. Warner JA, Miles EA, Jones AC, Quint DJ, Colwell BM, Warner JO. Is deficiency of interferon gamma production by allergen triggered cord blood cells a predictor of atopic eczema? Clin Exp Allergy 1994;24:423-430.

24. Prescott SL, Macaubas C, Smallacombe T, Holt BJ, Sly PD, Holt PG. Development of allergen-specific T-cell memory in atopic and normal children. Lancet 1999;353: 196-200.

25. Beyer D, Mitfessel H, Gillissen A. Maternal smoking promotes chronic obstructive lung disease in the offspring as adults. Eur J Med Res 2009;14 Suppl 4:27-31.

26. Hansen S, Strøm M, Maslova E, Dahl R, Hoffmann HJ, Rytter D, Bech BH, Henriksen TB, Granström C, Halldorsson TI, Chavarro JE, Linneberg A, Olsen SF. Fish oil supplementation during pregnancy and allergic respiratory disease in the adult offspring. J Allergy Clin Immunol 2017;139:104-111.e4.

27. Shinohara M, Wakiguchi $H$, Saito $H$, Matsumoto $K$. Symptoms of allergic rhinitis in women during early pregnancy are associated with higher prevalence of allergic rhinitis in their offspring. Allergol Int 2007;56:411-417.

28. Ushiyama Y, Matsumoto K, Shinohara M, Wakiguchi H, Sakai K, Komatsu T, Yamamoto S. Nutrition during pregnancy may be associated with allergic diseases in infants. J Nutr Sci Vitaminol (Tokyo) 2002;48:345-351.
29. Nakamura Y. Maternal and child health: work together and learn together for maternal and child health handbook. Japan Med Assoc J 2014;57:19-23.

30. Xepapadaki P, Manios Y, Liarigkovinos T, Grammatikaki E, Douladiris N, Kortsalioudaki C, Papadopoulos NG. Association of passive exposure of pregnant women to environmental tobacco smoke with asthma symptoms in children. Pediatr Allergy Immunol 2009;20:423-429.

31. Böhme M, Kull I, Bergström A, Nordvall SL, Wahlgren CF. Parental smoking increases the risk for eczema with sensitization in 4-year-old children. J Allergy Clin Immunol 2010;125:941-943.

32. Kramer U, Lemmen CH, Behrendt H, Link E, Schäfer T, Gostomyzyk J, Scherer G, Ring J. The effect of environmental tobacco smoke on eczema and allergic sensitization in children. Br J Dermatol 2004;150:111-118.

33. Vittinghoff $\mathrm{E}, \mathrm{McCulloch} \mathrm{CE}$. Relaxing the rule of ten events per variable in logistic and Cox regression. Am J Epidemiol 2007;165:710-718.

34. Tanaka K, Miyake Y, Sasaki S, Ohya Y, Hirota Y. Maternal smoking and environmental tobacco smoke exposure and the risk of allergic diseases in Japanese infants: the Osaka Maternal and Child Health Study. J Asthma 2008; 45:833-838.

35. Tanaka K, Miyake Y. Association between prenatal and postnatal tobacco smoke exposure and allergies in young children. J Asthma 2011;48:458-463.

36. Wang IJ, Hsieh WS, Wu KY, Guo YL, Hwang YH, Jee SH, Chen PC. Effect of gestational smoke exposure on atopic dermatitis in the offspring. Pediatr Allergy Immunol 2008; 19:580-586.

37. Thacher JD, Gruzieva O, Pershagen G, Neuman A, Wickman M, Kull I, Melen E, Bergström A. Pre- and postnatal exposure to parental smoking and allergic disease through adolescence. Pediatrics 2014;134:428-434.

38. Yi O, Kwon HJ, Kim H, Ha M, Hong SJ, Hong YC, Leem JH, Sakong J, Lee CG, Kim SY, Kang D. Effect of environmental tobacco smoke on atopic dermatitis among children in Korea. Environ Res 2012;113:40-45.

39. Murray CS, Woodcock A, Smillie FI, Cain G, Kissen P, Custovic A. Tobacco smoke exposure, wheeze, and atopy. Pediatr Pulmonol 2004;37:492-498.

Address correspondence to: Miwa Shinohara, MD, PhD

Department of Pediatrics

Ehime University Hospital

Shitsukawa, Toon-city, Ehime 791-0295

Japan

E-mail: shinohara.miwa.vv@ehime-u.ac.jp

Received for publication March 15, 2017; accepted after revision May 30, 2017. 